\title{
A Case of Secondary Myelodysplastic Syndrome Spontaneously Resolved by Discontinuance of Trimetazidine Dihydrochloride
}

\section{Dragomir Marisavljevic*}

Hematology Department, KBC "Bezanijskakosa" and Medical School, University of Belgrade, Belgrade, Serbia

\begin{abstract}
Treatment-related Myelodysplastic Syndrome (t-MDS) is well known and serious complication of cancer treatment. However, MDS cases caused by therapy of common nonmalignant diseases are unusual and represent diagnosic and therapeutic challenge. We experienced a case of secondary MDS, possibly induced by trimetazidine dihydrochloride, which was spontaneously resolved by discontinuance of the drug. The main purpose of this report is to point at the importance of continuous and careful monitoring of pharmacovigilance data of different medications and their possible "relation" with some diseases or pathological conditions which are, in fact, adverse drug event.
\end{abstract}

Keywords: Trimetazidine dihydrochloride; Myelodysplastic syndromes; Transitory; Spontaneous resolution; Adverse drug event

\section{Introduction}

Spontaneous "regression" of Myelodysplastic Syndromes (MDS) is uncommon. Some of the cases can be explained with the natural course of the disease [1], but some of the cases are treatment-related MDS spontaneously resolved by drug discontinuance [2]. Particularly troubling and serious clinical situation is when MDS, formerly defined as clonal hematological malignancy is related with commonly used drugs prescribed for treatment of common and frequent nonmalignant diseases.

We report a case of MDS related trimetazidine dihydrochloride which spontaneously resolved by drug discontinuance.

\section{Case Report}

A 73-years old male patient was admitted in July 2016. Due to the loss of body weight (15 kg for one year), periumbilical and low back pain. Patient's medical history revealed 15 years duration of arterial hypertension, acute myocardial infarction (in 2002) and permanent pacemaker (since 2008). His medication consisted of quinapril, lenkardipin, iso sorbitemononitrat and acetyl salicylic acid (from Year 2011) and trimetazidine dihydrochloride (from March 2016). Physical finding was inconclusive beside moderate scoliosis.

Full blood counts showed pancytopenia (Hb 120 g/l, WBC 2.16 $\times 10^{9} / \mathrm{L}$, platelets $80 \times 10^{9} / \mathrm{L}$ ) with normal differential. Biochemistry findings showed moderately elevated creatinine kinase $(220 \mathrm{U} / \mathrm{L}$, normal range: $<190 \mathrm{U} / \mathrm{L}$ ), lactate dehydrogenase (544 U/L, normal range: $270-428 \mathrm{U} / \mathrm{L})$, erythrocyte sedimentation rate $\left(60 / 1^{\text {st }} \mathrm{h}\right)$, C-reactive protein $(8.4 \mathrm{mg} / \mathrm{L}$, normal range: $0-5 \mathrm{mg} / \mathrm{L})$, D-dimer $(1330 \mathrm{ng} / \mathrm{ml}$, normal range: $<500 \mathrm{ng} / \mathrm{ml})$. Creatinine clearance was slightly reduced $(55.6 \mathrm{ml} / \mathrm{min})$. Immunological findings showed only elevated ANA IgG type (1:160). Serum vitamin D level was twice less than normal $(12.6 \mathrm{ng} / \mathrm{ml}$, normal range: $30-100 \mathrm{ng} / \mathrm{ml})$. However, PTH and TSH were in normal range, DEXA showed normal findings. Abdominal Computed Tomography (CT) showed only mesenterial oedema and significant spondylotic spine changes and dorsomedial intervertebral disc protrusion at the levels L4-L5 and L5S1. Gastroscopy and colonoscopy were normal. Chest radiography and thoracal CT showed infiltrative change in the right middle lobe of the lung. Fibrobronchoscopy showed plenty of thick pus drained from right branch, presumably from the middle lobe (compatible with "right middle lobe syndrome"). Microbiologically, sputum was sterile for the presence of fungi and bacteria (including acid resistant bacteria). Parenteral antimicrobial therapy was successful-chest radiography showed resolution of infiltrative change in right lobe, ESR and CRP came within normal range. Patient was discharged from hospital. However, follow up blood counts showed more profound pancytopenia which was the reason for performing a bone marrow trephine biopsy few months after first hospitalization. Pathohistological findings showed moderate 3 -lineage dysplasia with $9 \%$ of CD $34^{+} / \mathrm{CD} 117^{+}$blasts, finding indicative for Myelodysplastic Syndrome (MDS), refractory anemia with excess of blasts type 1 (RAEB 1). Cytogenetic findings showed normal karyotype (46, XY). After reassessment of patient's medical history and intense internet search [3], we decided to exclude trimetazidine dihydrochloride from his medication. One month after, his full blood counts became normal and remained unchanged until his sudden incidental death in March 2017.

\section{Discussion and Conclusion}

Treatment-related Myelodysplastic Syndrome (t-MDS) is well known and serious complication of cancer treatment. Relevant advances in knowledge of the risk factors, pathogenesis and treatment of t-MDS are recently achieved [4]. However, our knowledge on treatmentrelated MDS caused by therapy of common non-malignant diseases is limited. This is not only diagnostic pitfall or challenge, but also important therapeutic, ethical and legal issue. As Steensma poetically stressed that "Just as a pawnshop owner who is unable to distinguish a genuine Rolex ${ }^{\text {th }}$ watch from a cheap knockoff courts financial ruin, the physician who fails to discriminate between authentic Myelodysplastic Syndromes (MDS) and conditions resembling MDS risks misinforming or harming patients" [5]. This statement is published in article dedicated to distinguishing genuine MDS from "mimics, imitators, copycats and impostors" [5].

*Corresponding author: Prof. Dragomir Marisavljevic, KBC "Bezanijskakosa", Belgrade-11080, Serbia, Tel: +381-65-3357-090; Fax: +381-11-2699-937; E-mail: maris@tehnicom.net

Received April 26, 2017; Accepted June 08, 2017; Published June 15, 2017

Citation: Marisavljevic D (2017) A Case of Secondary Myelodysplastic Syndrome Spontaneously Resolved by Discontinuance of Trimetazidine Dihydrochloride. Adv Pharmacoepidemiol Drug Saf 6: 215. doi: 10.4172/2167-1052.1000215

Copyright: $\odot 2017$ Marisavljevic D. This is an open-access article distributed under the terms of the Creative Commons Attribution License, which permits unrestricted use, distribution, and reproduction in any medium, provided the original author and source are credited. 
Citation: Marisavljevic D (2017) A Case of Secondary Myelodysplastic Syndrome Spontaneously Resolved by Discontinuance of Trimetazidine Dihydrochloride. Adv Pharmacoepidemiol Drug Saf 6: 215. doi: 10.4172/2167-1052.1000215

Page 2 of 2

The main purpose of this report is to point at the importance of continuous and careful monitoring of pharmacovigilance data of different medications and their possible "relation" with some diseases or pathological conditions which are, in fact, adverse drug event. Thanks to credible clinical suspicion and absence of cytogenetic confirmation of disease clonality, we done internet search and noticed that FDA pharmacovigilance data between January 2004 and October 2014 recorded 485 Adverse Events (AE) for trimetazidine dihydrochloride. Among these reported AE two cases of MDS were registered, or $0.4124 \%$ of all reported AE. It is important to emphasize that FDA mainly receives reports of the most critical and severe cases, and therefore these numbers may underrepresent the complication rate of the medication. Concerning the fact that average percentage of all medicated patients where MDS is reported as a complication was only $0.0363 \%$ [3], we decided to exclude trimetazidine dihydrochloride from our patient's medication list. The result of our decision was prompt normalization of his blood counts. However, morphological regression of MDS was not proved since patient refused additional bone marrow examination.

\section{References}

1. Marisavljević D, Rolović Z, Ludoski-Pantić M, Djordjević V, Novak A (2005) Spontaneous remission in adults with primary myelodysplastic syndromes: incidence and characteristics of patients. Med Oncol 22: 407-410.

2. Nakagawa Y, Miura K, Yamazaki T, Ishizuka H, Takei K, et al. (2010) A case of treatment-related myelodysplastic syndrome spontaneously resolved by drug discontinuance. Int J Hematol 91: 530-533.

3. http://www.factmed.com/study-trimetazidine-causing-myelodysplastic $\% 20$ syndrome.php

4. Bhatia R, Deeg J (2011) Treatment-related myelodysplastic syndrome-molecular characteristics and therapy. Curr Opin Hematol 18: 77-82.

5. Steensma DP (2012) Dysplasia has a differential diagnosis: distinguishing genuine myelodysplastic syndromes (MDS) from mimics, imitators, copycats and impostors. Curr Hematol Malig Rep 7: 310-320. 